\title{
Chronic granulomatous disease, the McLeod phenotype and the contiguous gene deletion syndrome-a review
}

\author{
Casey E Watkins', John Litchfield², Eunkyung Song ${ }^{3}$, Gayatri B Jaishankar ${ }^{3}$, Niva Misra', Nikhil Holla², \\ Michelle Duffourc ${ }^{4}$ and Guha Krishnaswamy ${ }^{5^{*}}$
}

\begin{abstract}
Chronic Granulomatous Disease (CGD), a disorder of the NADPH oxidase system, results in phagocyte functional defects and subsequent infections with bacterial and fungal pathogens (such as Aspergillus species and Candida albicans). Deletions and missense, frameshift, or nonsense mutations in the gp91 ${ }^{\text {phox }}$ gene (also termed CYBB), located in the Xp21.1 region of the X chromosome, are associated with the most common form of CGD. When larger X-chromosomal deletions occur, including the XK gene deletion, a so-called "Contiguous Gene Deletion Syndrome" may result. The contiguous gene deletion syndrome is known to associate the Kell phenotype/McLeod syndrome with diseases such as X-linked chronic granulomatous disease, Duchenne muscular dystrophy, and Xlinked retinitis pigmentosa. These patients are often complicated and management requires special attention to the various facets of the syndrome.
\end{abstract}

Keywords: Granulomatous Disease, Chronic, gene deletion, XK Kell blood group precursor (McLeod phenotype), human, KX antigen, human, anemia, hemolytic

\section{Introduction}

Primary immune deficiencies can involve defects in phagocyte function, resulting in Chronic granulomatous disease (CGD) [1,2]. CGD is characterized by repeated infections with bacterial and fungal pathogens, as well as the formation of granulomas [1-4]. In this disease, the NADPH oxidase system is dysfunctional due to specific gene mutations, culminating in an inability of the phagocyte to eliminate pathogenic organisms. Typically, this defect in phagocyte function leads to serious infections including Staphylococcus aureus, Pseudomonas species, Nocardia species, fungi such as Aspergillus species, and Candida albicans. Significant morbidity and mortality may result.

The genetic defect in CGD can be transmitted in either an X-linked or autosomal recessive manner [1,5-7]. Genes regulating NADPH assembly and function

\footnotetext{
* Correspondence: krishnas@mail.etsu.edu

${ }^{5}$ Division of Allergy, Asthma and Clinical Immunology, Department of Medicine, Quillen College of Medicine, East Tennessee State University, Johnson City, Tennessee, USA

Full list of author information is available at the end of the article
}

are most commonly affected. When X-linked disease occurs, deletion of the contiguous genes that border the gene on the $\mathrm{X}$ chromosome that regulates NADPH function can result in the "contiguous $\mathrm{X}$-chromosome gene deletion syndrome" [8-12]. Mutations extending into these surrounding genes may result in Duchenne muscular dystrophy (DMD) or Retinitis pigmentosa $[13,14]$. Other conditions, such as the McLeod syndrome, may also result in such patients [15-18]. In some selected situations, mutations in other innate immune system genes such as the complement pathway genes (especially mannose binding lectin) may further complicate disease severity and management [19].

\section{CGD and the Contiguous Gene Deletion Syndrome}

$\mathrm{X}$-linked CGD is responsible for the majority $(>60 \%)$ of the CGD cases seen in the United States $[2,20]$. The Xlinked type is caused by a mutation in the gp91 ${ }^{\text {phox }}$ gene, which is also referred to as the cytochrome b-245 beta polypeptide (CYBB) gene. Autosomal recessive CGD is seen in the remaining $35 \%$ of cases and arises due to mutations of the other components of the 
NADPH oxidase system [1,2,5-7]. These mutations include $\mathrm{p} 22^{\mathrm{phox}}, \mathrm{p} 67^{\mathrm{phox}}$, and $\mathrm{p} 47^{\mathrm{phox}}$. Of these, the dominant mutation observed is in the $\mathrm{p} 22^{\text {phox }}$ gene which accounts for almost $25 \%$ of the autosomal recessive cases. The associated phenotypes are also referred to as the A22/A47/A67 CGD. The phenotype of the gp91 ${ }^{\text {phox }}$ gene mutation is referred to as X-CGD. Mutations of other nearby genes, $\mathrm{p} 40^{\mathrm{phox}}$ and Rac, have yet to be associated with any CGD phenotype $[2,20]$. Gene location and associated disease state are described in Table 1.

The CYBB gene spans a $30 \mathrm{~kb}$ region in the Xp21.1 region of the $\mathrm{X}$ chromosome (Figure 1A). Deletions and frameshift, missense, nonsense, or splice site mutations of the CYBB gene can contribute to defects seen in CGD. On occasion, larger X-chromosomal deletions may occur. The Kell locus or XK gene, which encodes an essential glycoprotein for Kell antigen expression, may be involved in such cases. These larger deletions that extend across multiple genes will result in manifestations of the "Contiguous gene deletion syndrome" (Figure 1B)[8,9]. As stated earlier, this syndrome (Figure 2) encompasses the McLeod syndrome in association with X-linked Chronic granulomatous disease, Duchenne muscular dystrophy, and/or X-linked Retinitis pigmentosa $[10,14,15]$.

\section{The Kell blood group and Kell antigens}

The Kell blood group system was first identified by Coombs in 1946 when ABO and Rhesus incompatibility were excluded in a mother, Mrs. Kelleher, who had delivered a baby with hemolytic anemia. It is now considered the third most important blood group system based on immunological potency. The antigens of the Kell system are numerous and complex [17,21-25]. The $\mathrm{K}$ antigen may be the most significant antigen of the Kell system with regards to development of disease and transfusion-related complications.

The Kell antigens, which are encoded for by the KEL gene, are carried by the transmembrane Kell glycoprotein (XK) (Figure 3). The KEL gene is found on chromosome 7 (7q33). It is highly polymorphic $[26,27]$ and encodes the numerous Kell antigens. There appear to be two major co-dominant alleles referred to as $\mathrm{k}$ (Cellano) and $\mathrm{K}$ (Kell) that differ by a single amino acid change; the latter is considered the more potent immunogen.

Although there have been 25 Kell antigens identified, the " $k$ " antigen is the most common. The phenotype $\mathrm{K}$ $\mathrm{k}+$ is seen in a majority of Caucasians and African Americans, while a smaller number (9\%) of Caucasians may be $\mathrm{K}+\mathrm{k}+$. When the Kell antigens are absent on red blood cells, this is referred to as the rare $\mathrm{K}$ null phenotype $\left(\mathrm{K}_{0}\right)$. Individuals with this phenotype produce anti$\mathrm{Ku}$ antibodies that target RBCs expressing Kell antigens, but are otherwise healthy. Anti-Ku antibodies may result in the development of moderate to severe transfusion reactions following transfusion from a donor who is Kell + . For this reason, patients with the $K_{0}$ phenotype should only be transfused with $\mathrm{K}_{0}$ blood products. Anti$\mathrm{Ku}$ antibodies are also involved in fetomaternal immunization. Pregnant females with the $\mathrm{K}_{0}$ phenotype produce anti-Ku antibodies which target Kell antigens located on the surface of fetal RBCs. These antibodies are responsible for the third most common cause of hemolytic anemia in the newborn. The McLeod phenotype is seen with a severe reduction in Kell antigens; this can be associated with CGD [23-25].

\section{The McLeod Syndrome}

The McLeod syndrome is characterized by an absence of the Kx antigen on red blood cells. This is associated with weak expression of Kell antigens. Kell antigens are covalently bound to the RBC transmembrane XK protein. When $\mathrm{XK}$ is absent on $\mathrm{RBC}$ membranes, McLeod syndrome develops. In this syndrome, the Kell antigens are weakly expressed which leads to the appearance of abnormally shaped RBCs (referred to as acanthocytes) [28]. Characteristics of the Kell and XK proteins are shown in Table 2 . The McLeod syndrome manifests either as a hemolytic anemia following transfusion of Kell(+) RBC to a Kell(-) recipient or as a delayed onset (usually in the $4^{\text {th }}$ decade or later) of neuropsychological or cardiovascular impairment in patients with CGD.

Table 1 Gene and Chromosomal localization

\begin{tabular}{|c|c|c|c|c|}
\hline Condition & Gene & Chromosome & Comments & Clinical \\
\hline X-linked CGD & CYBB & XP21 & $\begin{array}{l}\text { Deletion or missense, nonsense and/or frameshift mutations may } \\
\text { occur }\end{array}$ & $\begin{array}{l}\text { Opportunistic infection } \\
\text { Autoimmunity } \\
\text { Organ dysfunction }\end{array}$ \\
\hline $\begin{array}{l}\text { McLeod } \\
\text { syndrome }\end{array}$ & $X K$ & XP21 & $\begin{array}{l}\text { Absent Kx antigen and weak expression of Kell on RBC surface } \\
\mathrm{XK} \text { is linked to Kell blood group antigen } \\
\text { Kell locus mutations can also lead to the syndrome }\end{array}$ & $\begin{array}{l}\text { Acanthocytosis } \\
\text { Elevated CPK } \\
\text { Huntington's chorea-like disease } \\
\text { Muscle weakness and atrophy } \\
\text { Cardiomyopathy } \\
\text { Psychiatric disease Cognitive } \\
\text { impairment }\end{array}$ \\
\hline
\end{tabular}



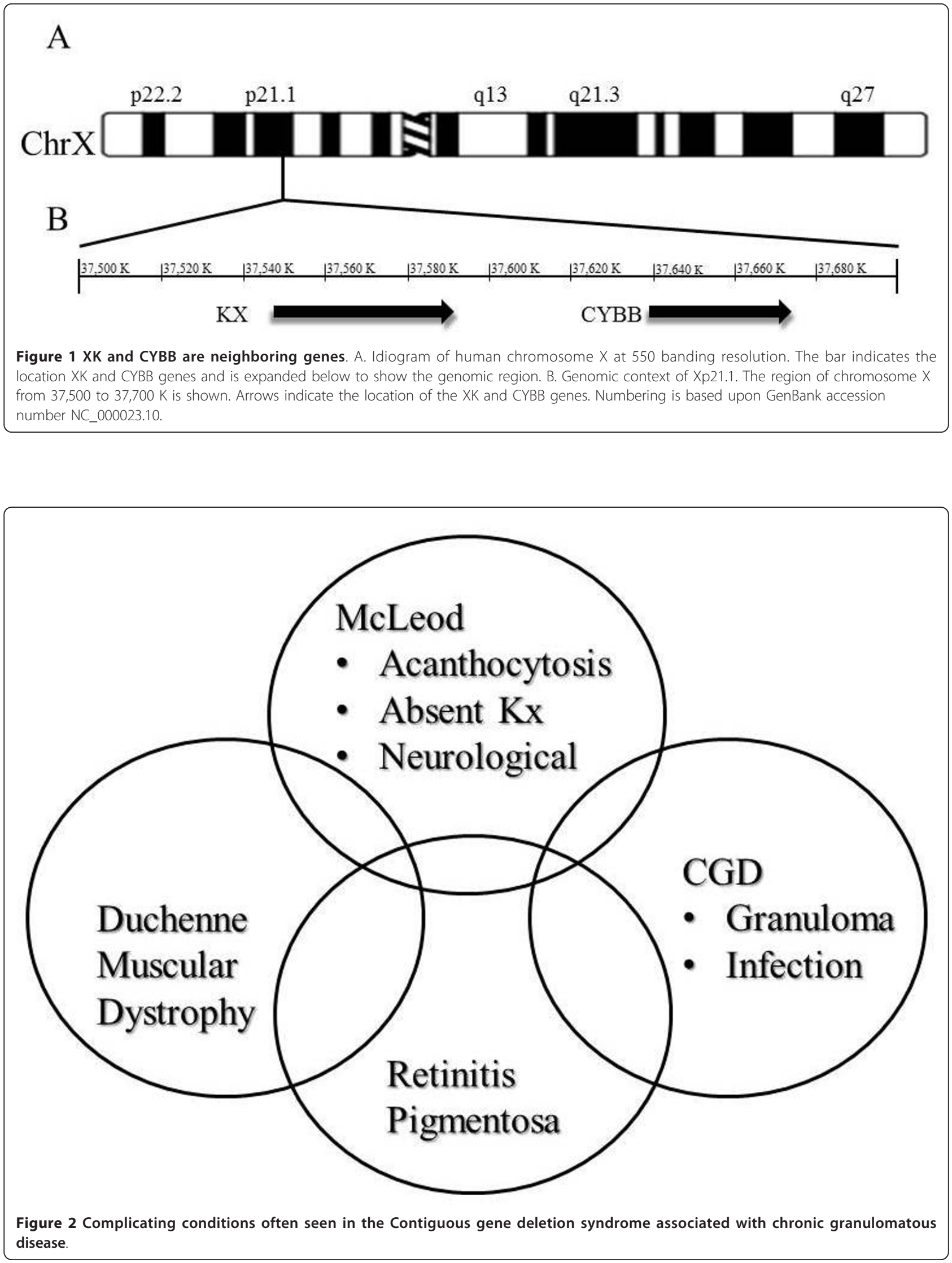


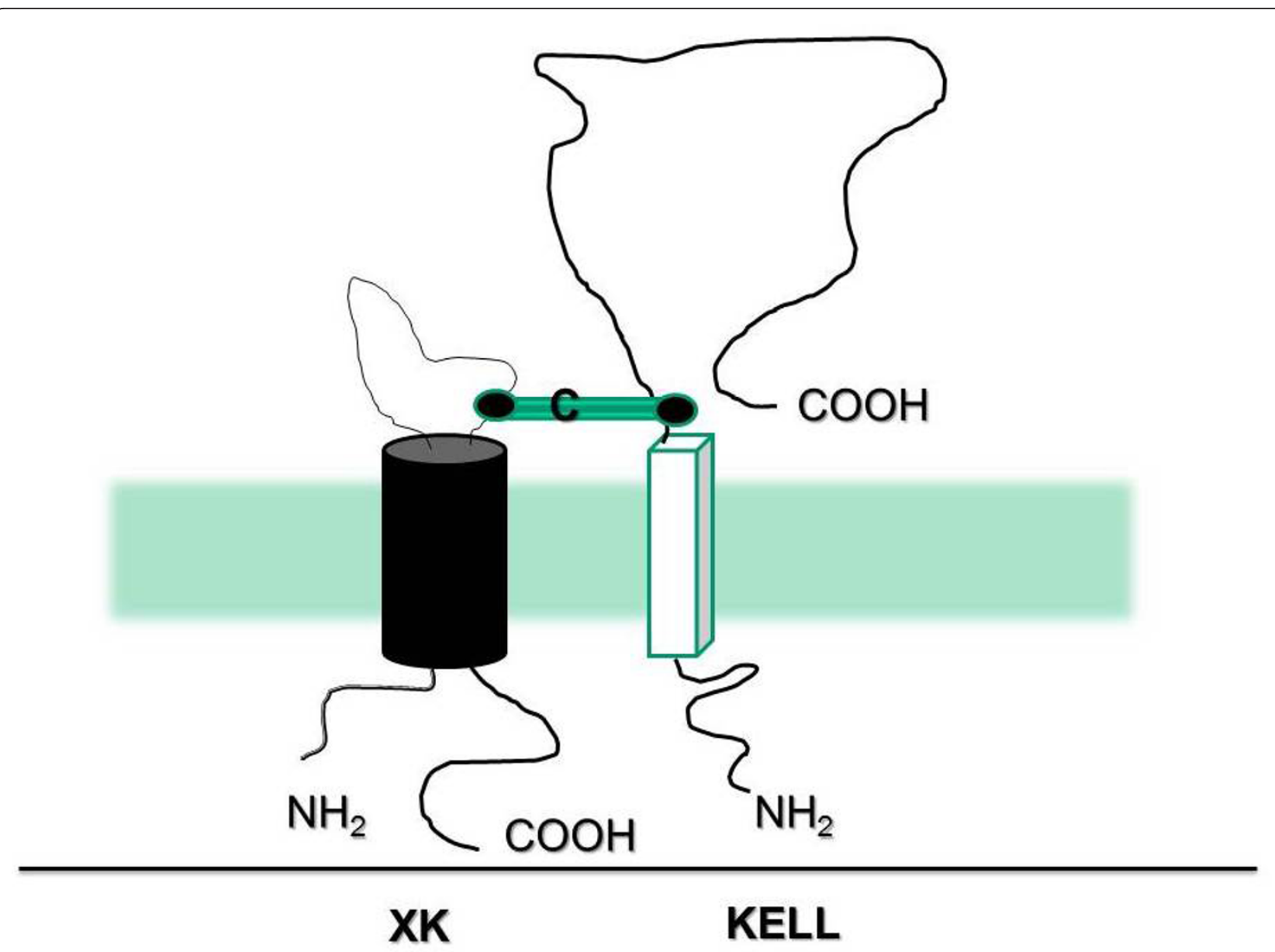

Figure 3 Structure of the XK and Kell proteins

Table 2 Characteristics of the Kell system

\begin{tabular}{ll}
\hline Kell & 93 kDa type II membrane glycoprotein \\
protein & Short N-terminal intracellular segment with one cysteine \\
& residue \\
& Single transmembrane section \\
& Large extracellular domain (665 amino acids with 15 \\
& cysteine residues) \\
& One cysteine residue (Cys72) in extracellular domain binds \\
& XK protein \\
& Homology to certain zinc endoproteases \\
& Demonstrates endothelin-3 converting enzymatic activity \\
& Encoded by the KEL gene (7q33) \\
& KO (null) RBC lack Kell antigens but have enhance XK \\
& activity \\
& KEL gene is inherited autosomally \\
& Molecular weight of 50.9 kDa \\
& 10 transmembrane segments \\
Short N-terminal domain (intracellular) \\
protein \\
Large C-terminal domain (intracellular) \\
A large hydrophilic loop (Figure 3) \\
Single cysteine residue that binds covalently to Cys72 on \\
Kell \\
Loss of XK leads to McLeod syndrome that has X-linked \\
inheritance
\end{tabular}

As reviewed by Jung et al., this disorder may be discovered accidentally by routine screening of apparently healthy blood donors [29]. Affected individuals may be detected by elevated creatinine kinase levels and acanthocytosis [29]. In addition to extravascular hemolytic anemia, patients manifesting the McLeod syndrome may develop multisystem disease, including splenomegaly and neurological problems late in life [30]. With time, neurological complications and manifestations of Huntington's disease-like disorder may become evident. The neurological symptoms may appear between the $2^{\text {nd }}$ and $6^{\text {th }}$ decades of life. Besides Huntington's chorea-like disease and cardiomyopathy, patients develop muscle weakness and atrophy, psychiatric disease, and cognitive impairment $[16,17,29-34]$. In some cases, the disorder that develops may be indistinguishable from neuroacanthocytosis with chorea, orofacial dyskinesia, dysarthria, and dementia [35]. It is therefore essential to evaluate these more complex patients for the conditions listed in Table 3 including generalized seizures and 
Table 3 Contiguous Gene Syndrome (including McLeod Syndrome) complicating CGD

\begin{tabular}{ll}
\hline Clinical component & Evaluation (selected) \\
\hline Myopathy & CPK level (serum) \\
& EMG/NCS \\
Hemolytic Anemia & Reticulocyte cell count \\
& Low haptoglobin \\
& Acanthocytosis \\
Late-onset neurological syndrome & \\
Cerebral atrophy & CT/MRI \\
Neuropathy & EMG/NCS \\
Huntington's chorea-like disease & CT/MRI \\
Neuropsychological and cognitive & Neuropsychological \\
impairment & testing \\
Myopathy/DMD & EMG/NCS \\
Seizures & Muscle biopsy* \\
Glomerulopathy with renal failure & EEG \\
& Serum creatinine level \\
& 24 hour urine analysis \\
& Renal imaging \\
Cardiovascular disease & $+/$ - kidney biopsy \\
Cardiomyopathy & \\
Arrythmia & ECHO \\
\hline
\end{tabular}

CPK = creatine phosphokinase; $\mathrm{EMG/NCS} \mathrm{=} \mathrm{electromyography} \mathrm{and} \mathrm{nerve}$ conduction study

$\mathrm{CT}=$ computed tomography; $\mathrm{MRI}=$ magnetic resonance imaging; $\mathrm{EEG}=$ electroencephalography

$\mathrm{ECHO}=$ echocardiography (transthoracic or transesophageal); EPS = electrophysiological studies

DMD = Duchenne muscular dystrophy; ${ }^{*}=$ typical muscle histology of DMD and absent muscle dystrophin

cardiomyopathy which may culminate in ventricular and atrial arrhythmia.

\section{Duchenne Muscular Dystrophy}

DMD is an X-linked progressive myopathy that can occasionally complicate a contiguous gene deletion syndrome involving X-linked CGD $[13,34]$. In the case reported by Kang et al., the DMD manifestations developed several years after the successful treatment of CGD by allogeneic stem cell transplantation [13]. This male child had a large scale deletion spanning the region between CYBB and DMD on the $\mathrm{X}$ chromosome. No dystrophin was expressed in the muscle, and a muscle biopsy demonstrated the typical histological changes of DMD. Dystrophin is located on the short arm of the $\mathrm{X}$ chromosome at the locus p21. Deletion of the dystrophin gene is commonly seen in DMD-especially when complicating CGD and the contiguous gene deletion syndrome. In other cases, point mutations and/or microdeletions may occur. Western blotting or immunocytochemistry for dystrophin protein expression can also be used diagnostically. The disease manifests as clumsy gait, development of the typical "Gower's maneuver" (the child has to place one hand on the knee in order to stand upright while rising from a seated position) and calf muscle changes (characterized by pseudo-hypertrophy). The child develops progressive muscular weakness that results in frequent falls, inability to climb and, eventually, culminates in the child becoming wheelchair bound. Cardiomyopathy and respiratory failure may result in severe morbidity and mortality. Treatment may involve physiotherapy, application of a brace, and surgery where indicated. Attempts are being made to develop pharmacological approaches (such as the use of glucocorticoids, not without adverse effects, or more muscle-specific therapies) and gene therapy to reverse the disease process.

\section{Retinitis Pigmentosa}

This is a condition that leads to progressive visual loss due to loss of the photoreceptors. There are several reports of Retinitis pigmentosa complicating CGD and the Contiguous gene deletion syndrome [14,34,36-38]. Ophthalmic examination reveals fairly typical findings including pigment loss, waxy pallor of the optic nerve head, and attenuation of the retinal arterioles. There are several genetic variants of Retinitis pigmentosa. The Xlinked type, involving mutations of the RPGR gene, is seen in the Contiguous gene deletion syndrome. Clinically, there is progressive loss of visual acuity and night blindness followed by a rapid decline in vision and blindness by the $4^{\text {th }}$ decade.

\section{Conclusion}

CGD is a chronic disease caused by a mutation in a gene encoding essential components of NADPH oxidase function. As a result, increased susceptibility for infections occurs. The more common form of CGD involves the gene regulating NADPH function that is located on the X-chromosome. A deletion that results in X-linked CGD can also involve contiguous genes. This results in the "contiguous $\mathrm{X}$-chromosome gene deletion syndrome" with manifestations of the McLeod syndrome, Duchenne muscular dystrophy and X-linked retinitis pigmentosa that further complicate disease severity and management.

\section{List of Abbreviations}

CGD: chronic granulomatous disease; CGS: contiguous gene syndrome; RBC: red blood cell; CYBB: cytochrome b-245 beta polypeptide.

\section{Acknowledgements}

We would like to thank Dr. David Adler of the Department of Pathology, University of Washington for the use of his idiogram of the X-chromosome depicted in Figure 1.

\section{Author details}

${ }^{1}$ Quillen College of Medicine, East Tennessee State University, Johnson City, Tennessee, USA. ${ }^{2}$ Department of Medicine, Quillen College of Medicine, East 
Tennessee State University, Johnson City, Tennessee, USA. ${ }^{3}$ Department of Pediatrics, Quillen College of Medicine, East Tennessee State University, Johnson City, Tennessee, USA. ${ }^{4}$ Department of Pharmacology, Quillen College of Medicine, East Tennessee State University, Johnson City, Tennessee, USA. ${ }^{5}$ Division of Allergy, Asthma and Clinical Immunology, Department of Medicine, Quillen College of Medicine, East Tennessee State University, Johnson City, Tennessee, USA.

\section{Authors' contributions}

CW-organized and assisted in writing manuscript; JL-assisted with manuscript review; ES-assisted in writing manuscript; GJ-assisted in writing manuscript; NM-assisted with manuscript review and corrections; $\mathrm{NH}$-assisted with figure and literature review; MD-assisted with generating figure; GKconceived of the manuscript, generated all figures and developed the format. All authors have read and approved the final manuscript.

\section{Competing interests}

The authors declare that they have no competing interests.

Received: 29 October 2011 Accepted: 23 November 2011 Published: 23 November 2011

\section{References}

1. Song E, Jaishankar GB, Saleh H, Jithpratuck W, Sahni R, Krishnaswamy G: Chronic granulomatous disease: a review of the infectious and inflammatory complications. Clin Mol Allergy 2011, 9:10.

2. Curnutte JT: Chronic granulomatous disease: the solving of a clinical riddle at the molecular level. Clin Immunol Immunopathol 1993, 67:S2-15.

3. Biggar WD, Buron S, Holmes B: Chronic granulomatous disease in an adult male: A proposed X-linked defect. J Pediatr 1976, 88:63-70.

4. Bylund J, Goldblatt D, Speert DP: Chronic granulomatous disease: from genetic defect to clinical presentation. Adv Exp Med Biol 2005, 568:67-87.

5. Casimir CM, Bu-Ghanim HN, Rodaway AR, Bentley DL, Rowe P, Segal AW: Autosomal recessive chronic granulomatous disease caused by deletion at a dinucleotide repeat. Proc Natl Acad Sci USA 1991, 88:2753-2757.

6. de BM, Hilarius-Stokman PM, Hossle JP, Verhoeven AJ, Graf N, Kenney RT, et al: Autosomal recessive chronic granulomatous disease with absence of the 67-kD cytosolic NADPH oxidase component: identification of mutation and detection of carriers. Blood 1994, 83:531-536.

7. Heyworth PG, Cross AR, Curnutte JT: Chronic granulomatous disease. Curr Opin Immunol 2003, 15:578-584.

8. Arai T, Zhao M, Kanegane H, van Zelm MC, Futatani T, Yamada M, et al Genetic analysis of contiguous X-chromosome deletion syndrome encompassing the BTK and TIMM8A genes. J Hum Genet 2011, 56:577-582.

9. Engelstad H, Carney G, S'aulis D, Rise J, Sanger WG, Rudd MK, et al: Large contiguous gene deletions in Sjogren-Larsson syndrome. Mol Genet Metab 2011, 104:356-361

10. Bertelson CJ, Pogo AO, Chaudhuri A, Marsh WL, Redman CM, Banerjee D, et al: Localization of the McLeod locus (XK) within Xp21 by deletion analysis. Am J Hum Genet 1988, 42:703-711.

11. Densen P, Wilkinson S, Mandell GL, Sullivan G, Oyen R, Marsh WL: Chronic granulomatous disease, $\mathrm{Kx}$ negative neutrophils and linkage with $\mathrm{Xg}$. Adv Exp Med Biol 1982, 141:655-658.

12. Densen P, Wilkinson-Kroovand S, Mandell GL, Sullivan G, Oyen R, Marsh WL: $\mathrm{Kx}$ : its relationship to chronic granulomatous disease and genetic linkage with Xg. Blood 1981, 58:34-37.

13. Kang PB, Lidov HG, White AJ, Mitchell M, Balasubramanian A, Estrella E, et al: Inefficient dystrophin expression after cord blood transplantation in Duchenne muscular dystrophy. Muscle Nerve 2010, 41:746-750.

14. Brown J, Dry KL, Edgar AJ, Pryde FE, Hardwick LJ, Aldred MA, et al: Analysis of three deletion breakpoints in Xp21.1 and the further localization of RP3. Genomics 1996, 37:200-210.

15. Russo DC, Oyen R, Powell VI, Perry S, Hitchcock J, Redman CM, et al: First example of anti-Kx in a person with the McLeod phenotype and without chronic granulomatous disease. Transfusion 2000, 40:1371-1375.

16. Uchida K, Nakajima K, Shima H, Ichiba K: The first example of the McLeod phenotype in a Japanese baby with chronic granulomatous disease. Transfusion 1992, 32:691.
17. Ho MF, Monaco AP, Blonden LA, van Ommen GJ, Affara NA, FergusonSmith MA, et al: Fine mapping of the McLeod locus (XK) to a 150-380-kb region in Xp21. Am J Hum Genet 1992, 50:317-330.

18. Bertelson CJ, Pogo AO, Chaudhuri A, Marsh WL, Redman CM, Banerjee D, et al: Localization of the McLeod locus (XK) within Xp21 by deletion analysis. Am J Hum Genet 1988, 42:703-711.

19. Miller C, Wilgenbusch S, Michaels M, Chi DS, Youngberg G, Krishnaswamy G: Molecular defects in the mannose binding lectin pathway in dermatological disease: Case report and literature review. Clin Mol Allergy 2010, 8:6.

20. Baehner RL: Chronic granulomatous disease of childhood: clinical, pathological, biochemical, molecular, and genetic aspects of the disease. Pediatr Pathol 1990, 10:143-153.

21. Sasaki M, Watanabe N: Kell blood group system and antibodies. Nippon Rinsho 2005, 63(Suppl 7):687-689.

22. Marsh WL: Chronic granulomatous disease, $\mathrm{Kx}$ antigen and the Kell blood groups. Prog Clin Biol Res 1978, 21:493-511.

23. Marsh WL: Chronic granulomatous disease, the McLeod syndrome, and the Kell blood groups. Birth Defects Orig Artic Ser 1978, 14:9-25.

24. Marsh WL: The Kell blood group, Kx antigen, and chronic granulomatous disease. Mayo Clin Proc 1977, 52:150-152.

25. Taswell HF, Lewis JC, Marsh WL, Wimer BM, Pineda AA, Brzica SM Jr: Erythrocyte morphology in genetic defects of the Rh and Kell blood group systems. Mayo Clin Proc 1977, 52:157-159.

26. Daniels $\mathrm{G}$ : The molecular genetics of blood group polymorphism. Hum Genet 2009, 126:729-742.

27. Lee $\mathrm{S}$ : The value of DNA analysis for antigens of the Kell and Kx blood group systems. Transfusion 2007, 47:32S-39S.

28. Witt TN, Danek A, Reiter M, Heim MU, Dirschinger J, Olsen EG: McLeod syndrome: a distinct form of neuroacanthocytosis. Report of two cases and literature review with emphasis on neuromuscular manifestations. J Neurol 1992, 239:302-306

29. Jung HH, Danek A, Frey BM: McLeod syndrome: a neurohaematological disorder. Vox Sang 2007, 93:112-121.

30. Hoger P, Seger R, Schenker T, Daniels GL, Irle U: Acanthocytosis in chronic septic granulomatosis: the McLeod syndrome. Monatsschr Kinderheilkd 1985, 133:296-299.

31. Frey D, Machler M, Seger R, Schmid W, Orkin SH: Gene deletion in a patient with chronic granulomatous disease and McLeod syndrome: fine mapping of the Xk gene locus. Blood 1988, 71:252-255.

32. Curnutte JT, Babior BM: Chronic granulomatous disease. Adv Hum Genet 1987, 16:229-297.

33. Branch DR, Gaidulis L, Lazar GS: Human granulocytes lack red cell Kx antigen. Br J Haematol 1986, 62:747-755.

34. Francke $\mathrm{U}$, Ochs $\mathrm{HD}$, de MB, Giacalone J, Lindgren V, Disteche $\mathrm{C}$, et al: Minor Xp21 chromosome deletion in a male associated with expression of Duchenne muscular dystrophy, chronic granulomatous disease, retinitis pigmentosa, and McLeod syndrome. Am J Hum Genet 1985, 37:250-267.

35. Stevenson VL, Hardie RJ: Acanthocytosis and neurological disorders. J Neurol 2001, 248:87-94.

36. Coman D, Yaplito-Lee J, La P, Nasioulas S, Bruno D, Slater HR, et al: Three Mendelian disorders (chronic granulomatous disease, retinitis pigmentosa, ornithine transcarbamylase deficiency) in a young woman with an X chromosome deletion, del(X)(p11.4p21.1). Mol Genet Metab 2010, 99:329.

37. de Saint-Basile G, Bohler MC, Fischer A, Cartron J, Dufier JL, Griscelli C, et al: Xp21 DNA microdeletion in a patient with chronic granulomatous disease, retinitis pigmentosa, and McLeod phenotype. Hum Genet 1988, 80:85-89.

38. Deardorff MA, Gaddipati H, Kaplan P, Sanchez-Lara PA, Sondheimer N, Spinner NB, et al: Complex management of a patient with a contiguous Xp11.4 gene deletion involving ornithine transcarbamylase: a role for detailed molecular analysis in complex presentations of classical diseases. Mol Genet Metab 2008, 94:498-502.

doi:10.1186/1476-7961-9-13

Cite this article as: Watkins et al: Chronic granulomatous disease, the McLeod phenotype and the contiguous gene deletion syndrome-a review. Clinical and Molecular Allergy 2011 9:13. 